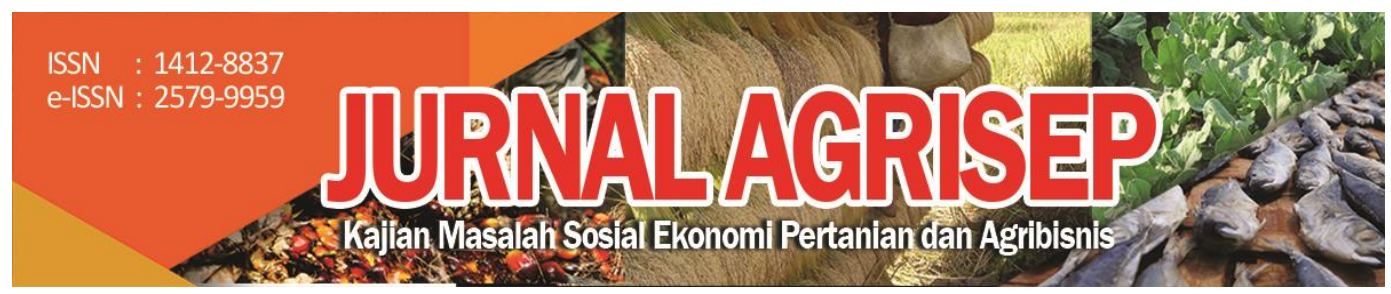

DOI: $10.31186 /$ jagrisep.20.1.1-12

\title{
PREFERENSI RISIKO PETERNAK SAPI PERAH DI KECAMATAN CISARUA KABUPATEN BOGOR PROVINSI JAWA BARAT
}

\author{
Risk Preference of Dairy Farmers in Cisarua District Bogor Regency \\ West Java Province \\ Rosita Noviana $\bigotimes_{1}$; Anna Fariyanti2); Ratna Winandi ${ }^{3)}$ \\ 1) Program Studi Magister Sains Agribisnis, Institut Pertanian Bogor \\ 2,3) Departemen Agribisnis, Institut Pertanian Bogor \\ Email: sita.noviana@gmail.com
}

\begin{abstract}
Cisarua District is one of the dairy farming centers with the lowest amount of milk production in Bogor Regency. The amount of milk production in Cisarua District is also known fluctuate. Differences in breeders' preferences in the use of production inputs affect production risk in dairy farming businesses. The aims of this research are to analyze the effect of production factors to production risk and risk preference of dairy farmers in Cisarua District. This research was conducted in Cisarua Subdistrict, Bogor Regency. The cross section data sourced from 91 dairy farmers were producing milk form second and third lactation cows. The model used in this research were Just and Pope model to analyze dairy farm risk production function and the Arrow-Pratt Absolute Risk Analysis model to analyze farmer's risk preferences. The results showed that forage and polar are risk reducing factors. Meanwhile, rice bran, tofu waste, concentrate, and work time are risk inducing factors in dairy farm. The risk preference of dairy farmers are risk taker to the use all of production inputs.
\end{abstract}

Keywords: dairy, farmer, preference, production, risk

\section{ABSTRAK}

Kecamatan Cisarua merupakan salah satu sentra peternakan sapi perah dengan jumlah produksi susu terendah di Kabupaten Bogor. Jumlah produksi susu di Kecamatan Cisarua juga diketahui berfluktuasi. Perbedaan preferensi peternak dalam penggunaan input produksi mempengaruhi risiko produksi pada usaha peternakan sapi perah. 
Penelitian ini dilakukan untuk mengetahui faktor produksi yang memengaruhi risiko produksi dan preferensi risiko para peternak sapi perah di Kecamatan Cisarua. Penelitian ini dilakukan di Kecamatan Cisarua, Kabupaten Bogor. Data yang digunakan merupakan data cross section dari 57 peternak yang memproduksi susu dari sapi laktasi kedua dan ketiga. Model yang digunakan dalam penelitian ini adalah model Just and Pope untuk menganalisis fungsi risiko produksi dan model Arrow-Pratt Absolute Risk Aversion untuk menganlisis preferensi risiko peternak. Berdasarkan hasil analisis diketahui bahwa input produksi yang bersifat risk reducing factor terdiri dari pakan hijauan, polar dan pengalaman beternak. Sementara, input produksi yang bersifat risk inducing factor diketahui meliputi, pakan dedak, ampas tahu, konsentrat, dan waktu kerja. Preferensi peternak hanya bersifat risk averse terhadap input produksi berupa ampas tahu.

Kata Kunci: peternak, preferensi, produksi, risiko, sapi perah

\section{PENDAHULUAN}

Subsektor peternakan di Indonesia terdiri dari berbagai jenis hewan yang diusahakan meliputi, ternak unggas, ternak sapi pedaging, ternak sapi perah, ternak kambing, dan hewan ternak lainnya. Susu merupakan salah satu komoditi yang diproduksi oleh subsektor peternakan khususnya usaha peternakan sapi perah. Usaha peternakan sapi perah merupakan salah satu usaha yang berkembang di Indonesia. Berdasarkan data Ditjen PKH (2018) diketahui bahwa jumlah populasi ternak sapi perah rata-rata meningkat sebanyak dua persen setiap tahunnya. Jumlah produksi susu pun terus mengalami peningkatan setiap tahunnya dengan rata-rata peningkatan sebanyak lima persen. Namun, diketahui bahwa jumlah impor susu merupakan jumlah impor terbesar diantara komoditi peternakan lainnya. Jumlah impor susu pun terbilang cenderung mengalami peningkatan setiap tahunnya. Kondisi yang demikian menggambarkan bahwa jumlah produksi susu nasional belum mampu memenuhi konsumsi masyarakat Indonesia.

Produktivitas susu di beberapa sentra usaha peternakan sapi perah di Indonesia pun bervariasi. Produktivitas susu di Kelurahan Pujon, Kabupaten Malang, Provinsi Jawa Timur terbilang cukup tinggi yaitu sebesar 12.26 liter/ekor/hari (Soeyatno 2013). Kabupaten Boyolali sebagai salah satu sentra produksi susu di Provinsi Jawa Tengah memiliki produktivitas susu sebesar 8.98 liter/ekor/hari (Aini 2016). Provinsi Jawa Barat adalah salah satu sentra produksi susu di Indonesia dengan produktivitas tertinggi yang mencapai 16.04 liter/ekor/hari di Kabupaten Lembang (Malau 2017). Namun, Kabupaten Bogor tepatnya di Kecamatan Cibungbulang sebagai salah satu sentra produksi susu lainnya di Provinsi Jawa Barat hanya mencapai produktivitas sebesar 9.45 liter/ekor/hari (Malau 2016). Terdapat beberapa sentra usaha peternakan sapi 
perah di Kabupaten Bogor meliputi Kecamatan Ciawi, Kecamatan Cibungbulang, Kecamatan Pamijahan dan Kecamatan Cisarua.

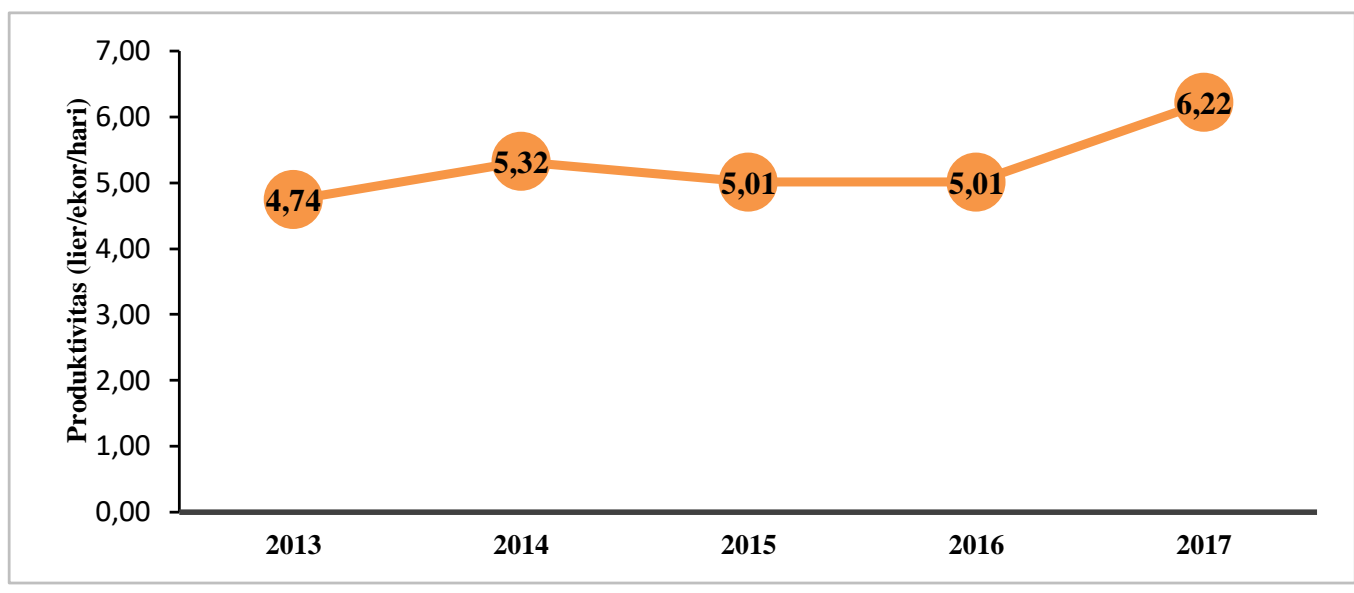

Gambar 1.

\section{Fluktuasi Produktivitas Susu Kecamatan Cisarua Sumber : BPS Kabupaten Bogor 2018}

Produktivitas rata-rata susu di Kecamatan Cisarua selama lima tahun dari tahun 2013 sampai tahun 2017 tercatat sebesar 5.26 liter/ekor/hari (BPS Kabupaten Bogor 2018). Tingkat produktivitas susu di Kecamatan Cisarua terbilang cukup rendah karena masih berada jauh di bawah tingkat produktivitas sentra produksi susu lainnya di Kabupaten Bogor. Rata-rata produktivitas susu di Provinsi Jawa Barat diketahui adalah sebesar 13.57 liter/ekor/hari sampai 14.78 liter/ekor/hari (Asmara 2015). Adanya gap antara produktivitas potensial di Provinsi Jawa Barat dengan produktivitas susu aktual di Kecamatan Cisarua mengindikasikan adanya risiko produksi pada usaha peternakan sapi perah di Kecamatan Cisarua. Selain itu, produktivitas susu di Kecamatan Cisarua pun diketahui berfluktuasi selama lima tahun seperti data yang disajikan pada Gambar 1.

Rendahnya produktivitas susu menyebabkan tingkat produksi susu menjadi relatif rendah. Tingkat produksi susu yang terbilang cukup rendah tersebut disebabkan karena faktor pakan yang kurang memadai. Pakan dan nutrisi merupakan faktor kunci yang mempengaruhi jumlah produksi susu (Devendra 2017). Risiko produksi yang terjadi pada usaha peternakan sapi perah juga dipengaruhi oleh faktor selain input produksi, seperti penyakit. Pemeliharaan kesehatan ternak juga teridentifikasi sebagai salah satu permasalahan yang menyebabkan terjadinya risiko pada usaha peternakan sapi perah (Septiani 2016). Penyakit yang menyerang ternak sapi perah merupakan faktor risiko yang paling berdampak terhadap usaha peternakan sapi perah di Belanda (Meuwissen et al. 2001). 
Preferensi risiko peternak sapi perah yang menjalankan usaha peternakannya secara konvensional akan berbeda dengan peternak sapi perah yang menjalankan usaha peternakan sapi perahnya secara organik (Flaten 2005). Kedua jenis peternak tersebut diketahui memiliki preferensi sebagai individu risk averse. Namun, peternak sapi perah konvesional diketahui lebih risk averse dibandingkan dengan peternak sapi perah organik. Perbedaan preferensi risiko tersebut mempengaruhi keputusan penggunaan input produksi pada masingmasing jenis peternak. Peternak sapi perah organik memberikan jumlah pakan konsentrat yang lebih sedikit dari jumlah pakan konsentrat yang diberikan oleh peternak sapi perah konvensional. Hal tersebut berdampak terhadap jumlah produksi susunya. Rata-rata peternak sapi perah organik menghasilkan susu yang lebih sedikit dari peternak sapi perah konvensional. Setiap peternak sapi perah memiliki keputusan yang berbeda-beda mengenai jenis dan jumlah pakan yang digunakan untuk ternak sapi perahnya. Peternak sapi perah di Kabupaten Lembang akan memberikan pakan hijauan rata-rata sebanyak 41.37 kg/ekor/hari (Malau 2017). Para peternak sapi perah di Pujon akan memberikan pakan hijauan rata-rata sebanyak $26.63 \mathrm{~kg} / \mathrm{ekor} / \mathrm{hari}$ (Soeyatno 2013). Perbedaan keputusan penggunaan pakan tersebut menggambarkan bahwa para peternak sapi perah memiliki preferensi risiko yang berbeda-beda terhadap penggunaan setiap faktor produksi. Berdasarkan uraian di atas maka tujuan dari penelitian ini meliputi : Menganalisis faktor produksi yang mempengaruhi risiko produksi susu pada usaha peternakan sapi perah di Kecamatan Cisarua dan menganalisis preferensi peternak sapi perah di Kecamatan Cisarua.

\section{METODE PENELITIAN}

\section{Jenis dan Sumber Data}

Penelitian dilaksanakan pada usaha peternakan sapi perah di wilayah Kecamatan Cisarua, Kabupaten Bogor. Lokasi penelitian ini ditentukan secara sengaja (purposive) dengan pertimbangan bahwa lokasi penelitian merupakan salah satu sentra peternakan sapi perah di Kabupaten Bogor dengan jumlah produksi susu terendah dan produktivitas yang berfluktuasi. Selain itu, tingkat produktivitas di Kecamatan Cisarua juga diketahui lebih rendah dari beberapa sentra produksi susu lainnya di Kabupaten Bogor.

Jenis data yang digunakan dalam penelitian ini adalah data cross section. Usaha peternakan sapi perah merupakan usaha dengan masa produksi setiap hari sepanjang tahun. Usaha peternakan sapi perah tidak dipengaruhi oleh musim dan siklus produksi. Penentuan sampel yang digunakan dalam penelitian ini dilakukan secara purposive kepada peternak yang sudah menjalankan usaha peternakan sapi perahnya selama minimal 3 tahun di Kecamatan Cisarua. Selanjutnya, pencatatan output produksi berupa hasil perahan susu akan dilakukan pada hewan ternak dalam masa laktasi kedua dan 
ketiga. Jumlah produksi susu sapi FH akan mengalami peningkatan pada setiap masa laktasinya. Jumlah produksi pada masa laktasi pertama sampai ketiga secara berurutan yaitu sebagai berikut, $27 \mathrm{~kg}, 31.70 \mathrm{~kg}$ dan $33.5 \mathrm{~kg}$ (Miglior et al. 2007). Kriteria tersebut digunakan agar data yang diperoleh dapat menggambarkan generalisasi dari sampel. Ternak sapi yang digunakan sampel merupakan ternak pada masa laktasi yang sama dengan jenis sapi FH (Friesian Holstein).

\section{Analisis Risiko Produksi Usaha Peternakan Sapi Perah}

Analisis risiko produksi yang dihadapi oleh peternak sapi perah akan dilakukan dengan menggunakan model yang dikembangkan oleh Just and Pope (1976). Model Just and Pope bisa menjelaskan bahwa produksi yang dihasilkan tidak hanya dipengaruhi oleh faktor produksi, tetapi juga dipengaruhi oleh faktor risiko (Robison dan Barry 1987). Fungsi produksi rata-rata dan fungsi risiko produksi (fungsi varians produktivitas) peternak sapi perah di Kecamatan Cisarua dapat digambarkan dalam sebuah model fungsi Just and Pope sebagai berikut :

Fungsi produksi rata-rata :

$$
\begin{aligned}
f(x) & =\operatorname{Ln} Y i \\
& =\beta 0+\beta 1 \operatorname{Ln} X 1 i+\beta 2 \operatorname{Ln} X 2 i+\beta 3 \operatorname{Ln} X 3 i+\beta 4 \operatorname{Ln} X 4 i+\beta 5 \operatorname{Ln} X 5 i+\beta 6 \operatorname{Ln} X 6 i+
\end{aligned}
$$

$$
\beta 7 \mathrm{LnD} 1 \mathrm{i}+\varepsilon
$$

Varians produktivitas dapat ditulis sebagai berikut :

$\sigma_{Y_{i}}^{2}=\left(Y_{i}-\bar{y}\right)^{2}$

Fungsi risiko produksi :

$\mathrm{h}(\mathrm{x})=\operatorname{Ln} \sigma^{2} \mathrm{Y}_{\mathrm{i}}$

$=\theta_{0}+\theta_{1} \operatorname{Ln} X_{1 \mathrm{i}}+\theta_{2} \operatorname{Ln} X_{2 \mathrm{i}}+\theta_{3} \operatorname{Ln} X_{3 \mathrm{i}}+\theta_{4} \operatorname{Ln} X_{4 \mathrm{i}}+\theta_{5} \operatorname{Ln} X_{5 \mathrm{i}}+\theta_{6} \operatorname{Ln} X_{6 \mathrm{i}}+\theta_{7} \operatorname{LnD}_{1 \mathrm{i}}+\varepsilon$.

$\sigma^{2} Y_{\mathrm{i}}=$ varians produktivitas hasil perahan susu; $\beta_{1}, \beta_{2}, \ldots, \beta_{7}=$ koefisien parameter dugaan input produksi peternakan sapi perah $\mathrm{X}_{1}, \mathrm{X}_{2}, \ldots, \mathrm{X}_{6}, \mathrm{D}_{1} ; \theta_{1}, \theta_{2}$, $\ldots, \theta_{7}=$ koefisien parameter dugaan input risiko peternakan sapi perah; $\mathrm{X}_{1}, \mathrm{X}_{2}$, $\ldots, \mathrm{X} 6, \mathrm{D}_{1} ; \mathrm{i}=$ peternak responden; $\varepsilon=$ unsur error.

Fungsi produksi menggambarkan hubungan antara setiap faktor produksi yang terdiri dari pakan hijauan (X1), dedak (X2), polar (X3), ampas tahu (X4), konsentrat pabrik (X5), dan lama waktu kerja peternak (X6) terhadap produktivitas aktual hasil perahan susu (Yi). Fungsi risiko menggambarkan hubungan antara setiap faktor produksi terhadap produktivitas hasil perahan susu rata-rata (Ŷi). Setiap faktor produksi pakan diukur dalam satuan 
$\mathrm{kg} / \mathrm{ekor} / \mathrm{hari}$, sedangkan faktor produksi tenaga kerja diukur dalam satuan jam/orang/hari. Produktivitas aktual dan produktivitas rata-rata diukur menggunakan satuan liter/ekor/hari. Kedua persamaan tersebut menggunakan penyakit sebagai dummy, dimana dummy bernilai satu menggambarkan ternak yang terserang penyakit dan dummy bernilai nol menggambarkan ternak yang sehat.

Koefisien parameter dugaan dari fungsi produksi yang bernilai positif menggambarkan bahwa semakin banyak input produksi yang digunakan maka rata-rata hasil produktivitasnya akan semakin meningkat, dan begitu pula sebaliknya. Nilai koefisien varian yang bertanda positif pada fungsi risiko menggambarkan bahwa faktor input produksi tersebut merupakan faktor input produksi yang meningkatkan risiko, dan begitu pula sebaliknya.

\section{Analisis Preferensi Risiko Peternak Sapi Perah}

Analisis preferensi risiko peternak dapat dilihat dengan menggunakan Arrow-Pratt absolute risk aversion (ARA) yang diperoleh dari rasio antara nilai SOC dan FOC dari fungsi utilitas dengan menggunakan persamaan sebagai berikut:

$A R=-\frac{U^{\prime \prime}\left(y_{i}\right)}{U^{\prime}\left(y_{i}\right)}$

Perbandingan dari negatif nilai turunan kedua fungsi utilitas $\left(\mathrm{U}^{\prime \prime}\right)$ terhadap nilai turunan pertama fungsi utilitas $\left(\mathrm{U}^{\prime}\right)$ menggambarkan nilai absolute risk aversion (AR). Menurut Robison and Barry (1987), peternak dapat dikatakan bersifat : (1) risk averse apabila AR > 0, (2) risk taker apabila AR < 0, dan (3) risk neutral apabila $\mathrm{AR}=0$.

\section{HASIL DAN PEMBAHASAN}

\section{Analisis Risiko Produksi Usaha Peternakan Sapi Perah}

Variabel-variabel input produksi yang digunakan dalam untuk menganilisis fungsi risiko produksi sama dengan input-input produksi yang digunakan pada fungsi produksi. Variabel input produksi tersebut merupakan variabel yang akan digunakan sebagai variabel independen di dalam model. Variabel dependen yang akan digunakan di dalam model fungsi risiko produksi adalah varian produktivitas susu. Nilai koefisien determinasi (R2) model fungsi produksi yang dihasilkan adalah sebesar 0.7233 . Nilai koefisein determinasi tersebut menggambarkan bahwa 72.33 persen keragaman produktivitas susu di Kecamatan Cisarua dapat dijelaskan secara bersama-sama oleh faktor input produksi di dalam model.

6 | Rosita Noviana, Anna Fariyanti, Ratna Winandi; Preferensi Risiko ... 
Estimasi fungsi risiko produksi usaha peternakan sapi perah juga dibentuk setelah model fungsi produksi memenuhi seluruh asumsi OLS. Berdasarkan hasil estimasi fungsi risiko produksi diketahui bahwa nilai koefisien determinasi (R2) yang dihasilkan adalah sebesar 0.2941. Nilai koefisien determinasi tersebut menggambarkan bahwa 29.41 persen keragaman varians produktivitas susu para peternak sapi perah di Kecamatan Cisarua dapat dijelaskan oleh seluruh faktor produksi yang digunakan dalam model.

Tabel 1. Hasil estimasi fungsi produksi usaha peternakan sapi perah di Kecamatan Cisarua tahun 2019

\begin{tabular}{lrcrr}
\hline \multicolumn{1}{c}{ Variabel } & Koefisien & $\begin{array}{c}\text { Robust } \\
\text { Standard } \\
\text { Error }\end{array}$ & t-hitung & $\mathrm{p}>\mathrm{t}$ \\
\hline Konstata & 0.7801 & 0.2675 & 2.92 & 0.005 \\
Hijauan & 0.4881 & 0.0872 & 5.60 & 0.000 \\
Dedak & 0.1075 & 0.0635 & 1.69 & 0.097 \\
Polar & 0.1553 & 0.0506 & 3.07 & 0.003 \\
Ampas tahu & -0.1499 & 0.0703 & -2.13 & 0.038 \\
Konsentrat & 0.1221 & 0.9960 & 1.23 & 0.226 \\
Waktu kerja & 0.0149 & 0.0769 & 0.19 & 0.847 \\
Dummy penyakit & -0.0427 & 0.0469 & -0.91 & 0.366 \\
\hline \multicolumn{1}{c}{ R-squared } & 0.7233 & & & \\
\hline
\end{tabular}

Sumber: Data Primer Diolah, 2019

Nilai koefisien determinasi untuk fungsi risiko produksi diketahui lebih besar dari nilai koefisien determinasi fungsi risiko produksi yang dihasilkan oleh penelitian Fanani (2015), Apriana (2017), dan Hartoyo (2018). Nilai koefisien determinasi untuk fungsi risiko produksi cenderung rendah karena model estimasi tersebut diperolah dari beberapa tahapan estimasi (Walter et al. 2014).

Koefisien variabel faktor produksi yang bertanda positif pada hasil estimasi fungsi risiko produksi menggambarkan bahwa penggunaan faktor produksi tersebut dapat meningkatkan risiko produksi atau disebut sebagai risk inducing factor. Beberapa faktor produksi yang termasuk ke dalam risk inducing factors antara lain, dedak, ampas tahu, konsentrat, dan waktu kerja. Koefisien variabel produksi yang bertanda negatif pada estimasi fungsi risiko produksi menggambarkan bahwa penggunaan faktor produksi tersebut dapat menurunkan risiko produksi atau disebut sebagai risk reducing factor. Faktor produksi yang dapat dikatakan sebagai risk reducing factors terdiri dari pakan hijauan dan polar.

Hijauan merupakan salah satu risk reducing factor yang secara signifikan mengurangi varians produktivitas pada taraf kepercayaan satu persen. Penambahan jumlah penggunaan pakan hijauan sebanyak satu persen dapat 
menurukan risiko produksi sebesar 4.6296 persen pada usaha peternakan sapi perah di Kecamatan Cisarua. Hal tersebut sejalan dengan hasil estimasi pada fungsi produksi untuk pakan hijauan yang bertanda prositif pada taraf kepercayaan satu persen.

\section{Tabel 2. Hasil estimasi fungsi risiko produksi usaha peternakan sapi perah di} Kecamatan Cisarua tahun 2019

\begin{tabular}{lrrrr}
\hline \multicolumn{1}{c}{ Variabel } & Koefisien & $\begin{array}{c}\text { Robust } \\
\text { Standard } \\
\text { Error }\end{array}$ & t-hitung & $\mathrm{p}>\mathrm{t}$ \\
\hline Konstata & 3.9617 & 3.6645 & 1.08 & 0.285 \\
Hijauan & -4.6296 & 1.6695 & -2.77 & 0.008 \\
Dedak & 0.7404 & 0.9025 & 0.82 & 0.416 \\
Polar & -0.9296 & 0.8511 & -1.09 & 0.280 \\
Ampas tahu & 2.5956 & 1.4872 & 1.75 & 0.087 \\
Konsentrat & 2.8132 & 1.3295 & 2.12 & 0.039 \\
Waktu kerja & 1.2703 & 1.5402 & 0.82 & 0.414 \\
Dummy penyakit & 2.7481 & 1.4488 & 1.90 & 0.064 \\
\hline R-squared & 0.2941 & \multicolumn{5}{c}{} \\
\hline
\end{tabular}

Sumber: Data Primer Diolah, 2019

Nilai koefisien pada fungsi produksi tersebut menggambarkan bahwa penambahan satu persen pakan hijauan akan meningkatkan produktivitas susu sebesar 0.4881 persen. Hasil estimasi ini sesuai dengan hasil penelitian Karuniawati (2013), Soeyatno (2013), Asmara (2015), dan Firlia (2017). Hijauan merupakan pakan utama bagi ternak sapi perah. Minimal pemberian pakan hijauan bagi ternak sapi perah adalah sebanyak 10 persen dari bobot tubuh sapi. Pakan hijauan merupakan sumber energi utama bagi ternak sapi perah.

Polar merupakan faktor input produksi lainnya dengan nilai koefisien yang bertanda negatif pada fungsi risiko produksi pada taraf kepercayaan di atas 20 persen. Hal tersebut sejalan dengan nilai koefisien polar pada fungsi produksi yang bertanda positif pada taraf kepercayaan satu persen. Penambahan penggunaan polar sebanyak satu persen dapat menurunkan risiko produksi susu sebesar 0.9296 persen dan dapat meningkatkan produktivitas susu sebesar 0.1553 persen. Asmara (2015) menyatakan bahwa penambahan polar sebagai pakan ternak sapi perah akan meningkatkan produksi susu pada peternakan rakyat di Provinsi Jawa Barat.

Penambahan penggunaan ampas tahu sebagai pakan ternak sapi perah sebanyak satu persen akan meningkatkan risiko produksi sebesar 2.5956 persen. Hal tersebut sejalan dengan nilai koefisien ampas tahu yang bertanda negatif pada fungsi produksi pada taraf kepercayaan lima persen. Penambahan penggunaan ampas tahu sebanyak satu persen akan menurunkan produktivitas susu sebanyak 0.1499 persen. Jumlah penggunaan ampas tahu yang terlalu 
banyak sebagai pakan pelengkap bagi ternak sapi perah akan menyebabkan penurunan produksi susu (Asmara 2015).

Penyakit digunakan sebagai variabel dummy pada penelitian ini dan diketahui bahwa nilai koefisiennya bertanda positif pada fungsi risiko dengan taraf kepercayaan sepuluh persen. Hal tersebut sejalan dengan nilai koefisien dummy penyakit pada fungsi produksi yang bertanda negatif pada fungsi produksi dengan taraf kepercayaan di atas 20 persen. Dengan demikian, adanya penyakit pada ternak sapi perah dapat menyebabkan peningkatan risiko produksi dan penurunan produktivitas susu. Penyakit merupakan sumber risiko produksi susu yang disebabkan oleh pemeliharaan ternak yang kurang baik sehingga kondisi kesehatan ternak mengalami penurunan (Septeani 2016).

Dedak merupakan risk inducing factor yang memengaruhi risiko produksi pada usaha peternakan sapi perah pada taraf kepecayaan di atas 20 persen. Penambahan penggunaan dedak sebagai pakan tambahan bagi ternak sapi perah akan menurunkan produksi susu (Asmara 2015). Hal tersebut juga dapat dipengaruhi oleh kualitas dari dedak yang diberikan lebih rendah dari kualitas konsentrat yang juga diberikan sebagai pakan tambahan. Selain itu, konsentrat juga merupakan risk inducing factor yang memengaruhi risiko produksi secara signifikan pada taraf kepercayaan lima persen.

Selanjutnya, faktor produksi berupa waktu kerja juga bertanda positif pada estimasi fungsi risiko produksi. Penambahan waktu kerja para peternak diduga dapat meningkatkan risiko produksi susu. Penambahan waktu kerja bagi para peternak menyebabkan penurunan stamina dan kesehatan para peternak sehingga berdampak terhadap kegiatan usaha peternakan sapi perah. Penambahan penggunaan tenaga kerja akan menyebabkan penurunan produksi susu (Karuniawati 2013).

\section{Preferensi Peternak Sapi Perah}

Perilaku peternak dalam menghadapi risiko produksi perlu diketahui setelah fungsi risiko produksi dan pengaruhnya diketahui terhadap pendapatan usaha peternakan sapi perah. Preferensi peternak dalam menghadapi risiko produksi mampu menjelaskan dan mencerminkan keputusan ekonominya (Akinola 2014).

Berdasarkan hasil analisis preferensi risiko diketahui bahwa rata-rata peternak sapi perah di Kecamatan Cisarua adalah risk taker terhadap seluruh faktor produksi yang terdiri dari hijauan, dedak, polar, ampas tahu dan konsentrat. Preferensi risiko peternak terhadap penggunaan hijauan dan polar dapat dikatakan sesuai dengan hasil estimasi fungsi risiko produksi. Para peternak berani mengambil risiko terhadap penggunaan pakan hijauan dan polar karena kedua variabel input produksi tersebut bersifat risk reducing factor. Para peternak tidak akan menahan penggunaan pakan hijaun dan polar dengan harapan akan mengurangi risiko produksi pada usaha peternakan sapi 
perahnya. Selain itu, berdasarkan hasil estimasi fungsi produksi diketahui bahwa penambahan jumlah input produksi berupa pakan hijauan dan polar mampu meningkatkan produktivitas susu.

Tabel 3. Preferensi risiko peternak sapi perah terhadap penggunaan input produksi di Kecamatan Cisarua

\begin{tabular}{lcc}
\hline \multicolumn{1}{c}{ Input Produksi } & Rata-rata Nilai AR & Preferensi Risiko \\
\hline Hijauan & -0.007330 & Risk Taker \\
Dedak & -1.439661 & Risk Taker \\
Polar & -0.257932 & Risk Taker \\
Ampas tahu & -0.346544 & Risk Taker \\
Konsentrat pabrik & -1.791453 & Risk Taker \\
\hline
\end{tabular}

Sumber: Data Primer Diolah, 2019

Rata-rata peternak sapi perah di Kecamatan Cisarua juga diketahui memiliki preferensi risiko sebagai risk taker terhadap penggunaan input produksi berupa dedak, ampas tahu dan konsentrat, meskipun ketiga faktor produksi tersebut bersifat risk inducing factor. Para peternak memiliki harapan untuk bisa mendapatkan hasil produksi susu yang lebih tinggi dengan menggunakan ketiga jenis pakan tersebut. Hal tersebut memperkuat hasil estimasi pada fungsi produksi yang menemukan bahwa penambahan input produksi berupa dedak dan konsentrat pabrik pada usaha peternakan sapi perah di Kecamatan Cisarua dapat meningkatkan produktivitas susu.

Para peternak sapi perah di Kecamatan juga memiliki preferensi risiko sebagai risk taker terhadap penggunaan ampas tahu meskipun berdasarkan hasil estimasi fungsi produksi diketahui bahwa penggunaan ampas tahu dapat menurunkan produktivitas susu di Kecamatan Cisarua. Hal tersebut dipengaruhi oleh harga ampas tahu yang terbilang murah diantara input-input produksi lainnya. Para peternak tetap melengkapi bobot pakan yang harus diberikan kepada ternak sapinya dengan menambahkan ampas tahu sebagai pakan tambahan. Penambahan jumlah ampas tahu terbilang sering dilakukan oleh para peternan untuk menghemat biaya produksi. Berdasarkan hasil analisis preferensi risiko tersebut dapat dikatakan bahwa para peternak sapi perah tidak menahan penggunaan ampas tahu.

\section{Simpulan}

\section{SIMPULAN DAN SARAN}

Berdasarkan hasil analisis diatas dapat diberikan kesimpulan sebagai berikut:

1. Variabel input produksi yang bersifat risk reducing factor diketahui terdiri dari pakan hijauan dan polar. Sementara itu, input produksi yang bersifat

10 | Rosita Noviana, Anna Fariyanti, Ratna Winandi; Preferensi Risiko ... 
risk inducing factor diketahui meliputi, pakan dedak, ampas tahu, konsentrat, dan waktu kerja.

2. Preferensi risiko para peternak sapi perah di Kecamatan Cisarua bersifat risk taker terhadap penggunaan seluruh faktor produksi pada usaha peternakan sapi perah.

\section{Saran}

Peternak diharapkan untuk melakukan pembelian pakan berupa hijauan untuk menambahkan jumlah pakan hijauan yang didapatkan dari hasil pengaritan karena pakan hijauan merupakan pakan utama bagi ternak sapi perah. Produktivitas susu menjadi semakin baik dengan ditambahkannya pakan berupa hijauan sehingga risiko produksi susu dapat diperkecil. Peternak diharapkan tidak mengurangi jumlah pemberian pakan berupa polar dan sebaiknya mengurangi pemberian pakan berupa ampas tahu. Meskipun harga polar terbilang lebih tinggi dibandingkan harga ampas tahu, tetapi penambahan jumlah penggunaan polar diketahui dapat meningkatkan produktivitas susu. Komponen biaya produksi untuk penyediaan ampas tahu dapat dialihkan untuk penyediaan polar. Dengan demikian, kemungkinan terjadinya risiko produksi dapat diperkecil.

\section{DAFTAR PUSTAKA}

Aini AN. 2016. Analisis Biaya Transaksi pada Usaha Sapi Perah di Kabupaten Boyolali, Jawa Tengah. [tesis]. Bogor: Sekolah Pascasarjana, Institut Pertanian Bogor.

Akinola BD. 2014. Risk Preference and Coping Strategies Among Poultry Farmers in Abeokula Metropolis Nigeria. Global Journal Inc (USA). 14(5):22-29.

Apriana N. 2017. Analisis Risiko Produksi Petani Padi di Daerah Aliran Sungai Bengawan Solo, Kabupaten Bojonegoro, Provinsi Jawa Timur. [tesis]. Bogor: Sekolah Pascasarjana, Institut Pertanian Bogor.

Asmara A, Purnamadewi YL, Lubis D. 2015. Keragaan Produksi Susu dan Efisiensi Usaha Peternakan Sapi Perah Rakyat di Indonesia. Jurnal Manajemen dan Agribisnis. 13(1): 14-25.

Badan Pusat Statistik Kabupaten Bogor. 2018. Kabupaten Bogor Dalam Angka 2018. BPS Kabupaten Bogor.

Devendra C. 2007. Constraint analysis to improve integrated dairy production systems in developing countries: The importance of participatory rural appraisal. Tropical Animal Health and Production. 39(8): 549-556. 
[Ditjen PKH] Direktorat Jenderal Peternakan dan Kesehatan Hewan. 2018. Statistik Peternakan dan Kesehatan Hewan. Jakarta (ID): Kementerian Pertanian.

Flaten O, Lien G, Koesling M, Valle PS, Ebbesuik M. 2005. Comparing Risk Perception and Risk Management in Organic and Conventional Dairy Farming: Emperical Results From Norway. Livestock Production Science. 95: (11-25).

Hartoyo KL. 2018. Risiko Produksi dan Preferensi Risiko Petambak Udang Vanamei di Kabupaten Subang Provinsi Jawa Barat. [tesis]. Bogor: Sekolah Pascasarjana, Institut Pertanian Bogor.

Just RE, Pope RD. 1976. On the relantionship of input decisions and risk. California Agricultural Experiment Station. University of California.

Karuniawati R, Fariyanti A. 2013. Faktor-Faktor yang Mempengaruhi Produksi Susu Sapi Perah di Kecamatan Megamendung Kabupaten Bogor Provinsi Jawa Barat. Forum Agribisnis. 3(1): 73-86

Malau LRE. 2016. Pendapatan Usahaternak Sapi Perah Anggota KPS Bogor (Kasus: KUNAK Cibungbulang dan Kelurahan Kebon Pedes) [skripsi]. Bogor: Fakultas Ekonomi dan Manajemen, Institut Pertanian Bogor.

Malau LRE. 2017. Pengaruh Layanan Usaha Koperasi dan Tingkt Partisipasi Anggota Terhadap Efisiensi Produksi Usaha Ternak Sapi Perah (Kasus: KPSBU Lembang, Jawa Barat). [tesis]. Bogor: Sekolah Pascasarjana, Institut Pertanian Bogor.

Meuwissen MPM, Huirne RBM, Hardaker JB. 2001. Risk and Risk Management: An Empirical Analysis of Dutch Livestock Farmers. Journal of Livestock Production Science 69: 43-53.

Miglior F, Sewalem A, Jamrozik J, Bohmanova J, et al. 2007. Genetic Analisis of Milk Urea Nitrogen and Lactose and Their Relationships with Other Production Traits in Canadian Holstein Cattle. J Dairy Sci. 90 : 2468-2479.

Robinson LJ, Barry PJ. 1987. The Competitive Firm's Response to Risk. London: Macmillan Publisher.

Septiani W. 2016. Rancang Bangun Model Manajemen Risiko Rantai Pasok Agroindustri Susu Berbasis Pengetahuan. [disertasi]. Bogor: Sekolah Pascasarjana, Institut Pertanian Bogor.

Soeyatno RF. 2013. Analisis Pendapatan dan Faktor-faktor yang Mempengaruhi Produksi Susu di Desa Pandesari Kecamatan Pujon Kabupaten Malang Jawa Timur [tesis]. Bogor: Sekolah Pascasarjana, Institut Pertanian Bogor.

Walter JT, Roberts RK, Larson JA, English BC, Howard DD. 2004. Effects of Risk, Disease, and Nitrogen Source on Optimal Nitrogen Fertilization Rates in Winter Wheat Production [Working Paper]. Oklahoma. Southern Agricultural Economic Association

12 | Rosita Noviana, Anna Fariyanti, Ratna Winandi; Preferensi Risiko ... 